Original Research Article

\title{
A study on the effect of topical lidocaine gel versus drops on surgeon's comfort during manual small incision cataract surgery
}

\author{
Prakash Krishnan $^{1}$, Sancy Mary Sam ${ }^{1 *}$, Sanitha Kuriachan ${ }^{1}$, Nirmala Sethuraman²
}

\begin{abstract}
${ }^{1}$ Department of Pharmacology, Al Azhar Medical College and Super Speciality Hospital, Thodupuzha, Kerala, India ${ }^{2}$ Department of Pharmacology, Vinayaka Mission's Kirupananda Variyar Medical College, Salem, Tamilnadu, India, India
\end{abstract}

Received: 24 May 2018

Revised: 01 June 2018

Accepted: 06 June 2018

\section{*Correspondence to:}

Dr. Sancy Mary Sam,

Email: sms_gis@yahoo.com

Copyright: (C) the author(s), publisher and licensee Medip Academy. This is an openaccess article distributed under the terms of the Creative Commons Attribution NonCommercial License, which permits unrestricted noncommercial use, distribution, and reproduction in any medium, provided the original work is properly cited.

\begin{abstract}
Background: Cataract is a frequent surgical procedure performed worldwide. The study compared lidocaine $4 \%$ drops with $2 \%$ gel on surgeon's comfort, need for supplemental anaesthesia and duration of surgery in patients who underwent manual small incision cataract surgery.

Methods: This was a Prospective, Comparison study conducted at a Single centre by multiple surgeons. Patients enrolled for surgeries were divided into Group A: Lidocaine $4 \%$ drops $1 \mathrm{ml}$ was instilled in the conjunctival sac 5 minutes before surgery and Group B: Lidocaine $2 \%$ gel $2 \mathrm{ml}$ was applied. Endpoints evaluated were surgeon's comfort, need for supplemental anesthesia and duration of surgery.

Results: The mean duration of surgery for gel was $20 \pm 8$ minutes as compared to $29 \pm 6$ minutes with drops ( $\mathrm{p}^{*}$ - value<0.001). $26(87 \%)$ patients in gel did not require any supplemental anesthesia as compared to $3(10 \%)$ patients in drops. Peribulbar supplementation was required for $20(67 \%)$ patients in drops as compared to $1(3 \%)$ patient in gel ( $\mathrm{p}^{*}$ - value<0.001). $26(87 \%)$ patients in gel were operated comfortably by the surgeon as compared to $2(6 \%)$ patients in drops. Mild to Moderate discomfort was experienced by the surgeon in operating $27(90 \%)$ patients in drops as compared to $3(10 \%)$ patients in gel $\left(\mathrm{p}^{*}\right.$ value<0.001).

Conclusions: The surgeons were more comfortable using gel with least requirement of supplemental anaesthesia and faster completion compared to drops.
\end{abstract}

Keywords: Lidocaine gel, Lidocaine drops, MSICS, Surgeon's comfort, Topical anaesthesia

\section{INTRODUCTION}

The developing countries bear $90 \%$ of the burden of blindness according to a WHO survey. Cataract accounts for $65 \%$ among them. ${ }^{1,2}$ Cataract surgery is a high frequency surgery with a yearly rate approaching $1 \%$ of the entire population. ${ }^{3}$

This remains one of the most cost-effective surgical interventions in terms of quality of life restored. The manual small incision cataract surgery (MSICS) is the surgery of choice for the high-volume needed in developing countries. Phacoemulsification which is the state-of-the-art technique is unsuitable owing to high cost and steep learning curve., ${ }^{4,5}$

Authors compared the two topical preparations of lidocaine - $4 \%$ drops with $2 \%$ gel based on surgeon's comfort, need for supplemental anaesthesia and duration of surgery in patients who underwent manual small incision cataract surgery. 


\section{METHODS}

This was a Prospective, Comparison study conducted from November 2012 to May 2013 at a Single centre by multiple surgeons.

\section{Study population}

Patients posted for manual small incision cataract surgery in ophthalmology department of Vinayaka Mission's Kirupananda Variyar Medical College, Salem.

The institutional ethical committee approved the study. All cataract patients posted for manual small incision cataract surgery were screened and selected based on the following criteria

\section{Inclusion criteria}

Patients included in the study were of both sexes aged 50 and above.

\section{Exclusion criteria}

Patients Below 50 years, Pregnant woman, Lactating mother were excluded. Those suffering from Shock, Epilepsy, Complete heart block, Congestive heart failure, Porphyria were also exempted. Patients allergic to lidocaine or having impaired cardiac, respiratory, renal, hepatic impairments were not considered for the study.

The procedure was explained to each patient and their bystander and a written informed consent form was given on the day before surgery. All consenting patients received a test dose of lidocaine subcutaneously in the forearm. Then Ofloxacin eye drops was administered every two hours in both the eyes. One hour prior to surgery, Tropicamide and Phenylephrine eye drops were instilled till complete dilatation of pupil.

The patients were divided into two groups by administering alternate patients with drops and gel. It was done in 1:1 ratio as per their inpatient register number.

Systematic sample type of sample was used in this study. The 60 patients underwent MSICS, out of which 30 each received drops and gel.

\section{Group A}

There were 5 minutes prior to surgery, Lidocaine $4 \%$ drops [LOX 4\%,NEON] $1 \mathrm{ml}$ was instilled in the conjunctival sac.

\section{Group B}

There were 5 minutes prior to surgery, Lidocaine $2 \%$ gel [LOX 2\%,NEON] $2 \mathrm{ml}$ was applied over the palpebral conjunctiva.
Then both the groups underwent manual small incision cataract surgery by multiple surgeons. At the end of surgery, the eye was covered after subconjunctival injection of Gentamicin and Dexamethasone.

The surgeon's comfort was scored on the following scale: ${ }^{6}$

- Severe discomfort, surgeon is unable to continue the surgical technique;

- Moderate discomfort, the surgical technique is performed with great difficulty;

- Mild discomfort - restricts the surgical technique at some moments during the procedure;

- Comfortable, interferes with the surgical technique at some moments because of movement of the eyeball;

- Very comfortable, does not interfere with the surgical technique.

The following were also recorded:

The duration of surgery in minutes,

- $\quad$ Starting time;

- Closing time;

- Total time;

Need for supplemental anesthesia either:

- None

- $\quad$ Topical (Lidocaine 4\% drops)

- Intracameral (2\% preservative free lignocaine)

- $\quad$ Peribulbar (2\% lignocaine and bupivacaine)

\section{Statistical analysis}

SPSS software version 16 was used to analyze the data obtained. Descriptive statistics including the mean and standard deviation were calculated for quantitative variables. Qualitative variables were expressed as percentages and frequency distribution pattern was noted. Comparison between qualitative variables was performed using the chi square $\left(\mathrm{X}^{2}\right)$ test. Quantitative variables were compared with paired sample Student's t-test.

\section{RESULTS}

The patients who received Lidocaine drops were aged $69 \pm 7$ years and that of Lidocaine gel were aged $55 \pm 5$ years. Of the 30 patients who received drops 19 were females and 11 were males. Of the 30 patients who received gel 28 were males and 2 were females. The study evaluated Surgeon's comfort, Need for supplemental anesthesia and Duration of surgery.

\section{Duration of surgery}

As shown in Figure 1, in gel group $12(40 \%)$ patients completed surgery in $<15$ minutes as compared to 0 patients in drops group. Whereas $27(90 \%)$ patients in 
drops group completed surgery in 15-30 minutes as compared to $14(47 \%)$ patients with gel group. The difference was statistically significant, $(\mathrm{p} *$ - value $=0.001)$. In gel group 3 (10\%) patients completed surgery in 30-45 minutes as compared to $2(7 \%)$ patients in drops group. A time of 45-60 minutes was required for $1(3 \%)$ patient each in both groups.

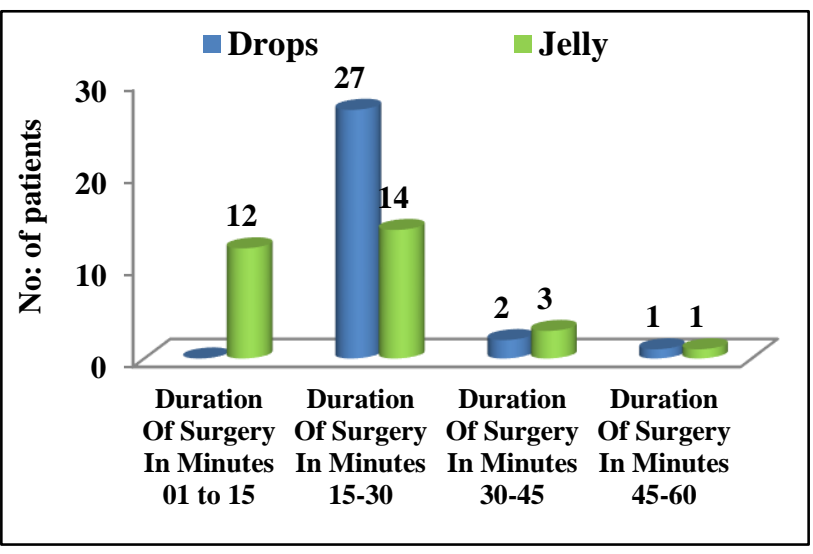

Figure 1: Distribution of patient based on duration of surgery in minutes and local anesthetic formulation used in eye.

As shown in Figure 2, the mean duration of surgery for gel group was $20 \pm 8$ minutes as compared to $29 \pm 6$ minutes with drops group. The difference was statistically significant, $\left(\mathrm{p}^{*}\right.$ - value $\left.<0.001\right)$.

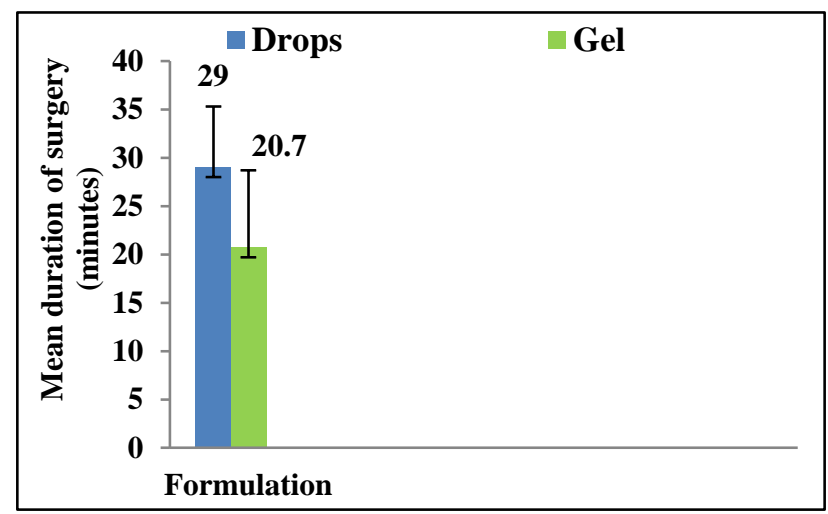

Figure 2: Comparison of duration of surgery in minutes, among local anesthetic drops and gel used in eye.

\section{Need for supplemental anesthesia}

As shown in Figure 3, 26 (87\%) patients in gel group did not require any supplemental anesthesia as compared to 3 $(10 \%)$ patients in drops group. Topical supplementation of Lidocaine $4 \%$ drops was required for 7 (23\%) patients in drops group as compared to $2(7 \%)$ patients in gel group. Intracameral supplementation of $2 \%$ preservative free lignocaine was required for $1(3 \%)$ patient in gel group as compared to 0 patients in drops group. Peribulbar supplementation of $2 \%$ lignocaine and bupivacaine was required for $20(67 \%)$ patients in drops group as compared to $1(3 \%)$ patient in gel group. The difference was statistically significant, $\left(\mathrm{p}^{*}\right.$ - value $\left.<0.001\right)$.

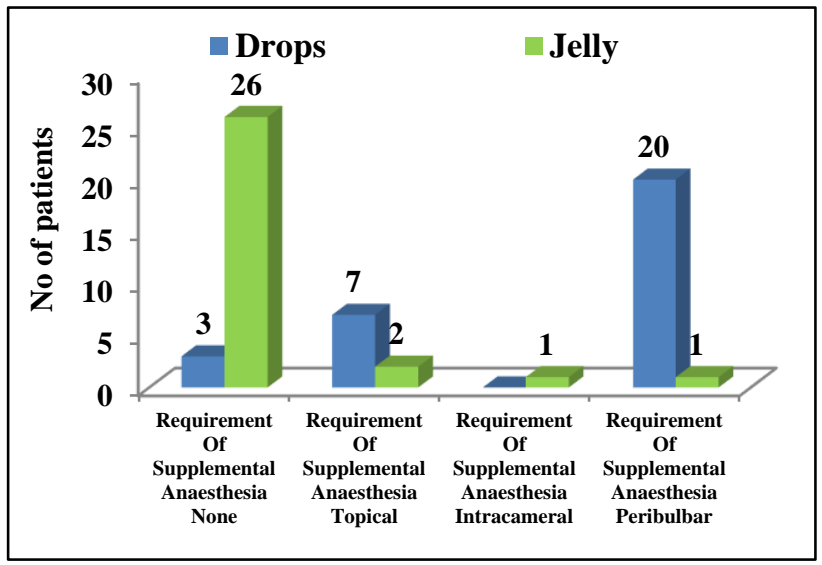

Figure 3: Distribution of patient based on requirement of supplemental anesthesia and local anesthetic formulation used in eye.

\section{Surgeon's comfort score}

As shown in Figure 4, 12 (40\%) patients in gel group were operated very comfortably as compared to $1(3 \%)$ patient in drops group. $14(47 \%)$ patients in gel group were operated comfortably as compared to $1(3 \%)$ patient in drops group. Mild discomfort was experienced in operating $14(47 \%)$ patients in drops group as compared to $2(7 \%)$ patients in gel group (1 of them received supplemental anesthesia with topical Lidocaine $4 \%$ drops and the other received intracameral $2 \%$ preservative free lignocaine). Moderate discomfort was experienced in operating $13(43 \%)$ patients in drops group as compared to 1 (3\%) patient in gel group (received supplemental anesthesia with Peribulbar 2\% lignocaine and bupivacaine). The difference was statistically significant, $\left(\mathrm{p}^{*}\right.$ - value $\left.<0.001\right)$. Severe discomfort was experienced in operating $1(3 \%)$ patient in each group.

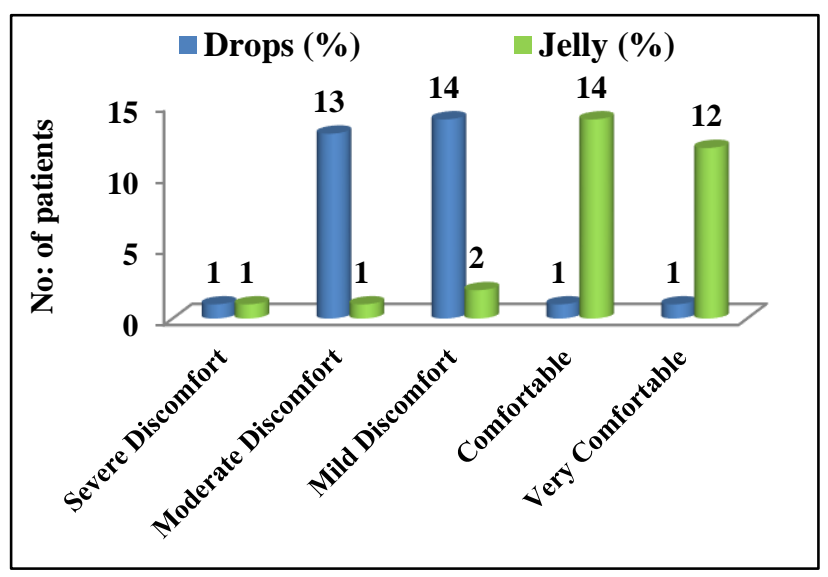

Figure 4: Distribution of patient based on surgeon's comfort score and local anesthetic formulation used in eye. 


\section{DISCUSSION}

In this study, 30 patients $(50 \%)$ each received Lidocaine drops and gel formulations. The present study has analyzed the effects of Lidocaine $4 \%$ drops and $2 \%$ gel in patients who underwent manual small incision cataract surgery from the surgeon's point of view. Authors observed that, completion of surgery was faster with gel than drops. The Need for supplemental anesthesia was more for drops than gel. Thus from the ophthalmologic surgeon's point of view, his comfort level was better with gel. This may be an indirect effect of better patient cooperation and lesser requirement of supplemental anesthesia with faster completion.

In comparison with other routes, there is no preoperative pain on topical application. This may be due to the absence of stimulation of sympathetic system by topical application. $^{7}$

Conventionally used injection technique had preoperative pain as well as the mild to very severe complications; hence application of topical gel seems to be better option in patient care. ${ }^{8-12}$ These advantages of gel could be due to the increased contact time and prolonged duration of action of 20-25 minutes as compared to 15-20 minutes for drops. ${ }^{13,14}$

In $90 \%$ of gel patients the duration of surgery is similar to the average time with injection technique, showing similar surgeon's comfort.

A study done by Bardocci A, et al, concluded that, if administered by means of gel, the same amount of Lidocaine gives significantly higher intracameral levels of Lidocaine, better analgesia, better patient cooperation, and less need for intraoperative supplemental anesthesia. ${ }^{15}$

\section{CONCLUSION}

Hence the conclusion from this study is that the surgeon was more comfortable using gel with least requirement of supplemental anesthesia and faster completion compared to drops.

The drawbacks in this study are an unequal distribution of age and sex of patients, small sample size. More aged and female fell in the drops group. However, we could not control this difference as patients were allotted systematically into alternate group as per their inpatient register number. Further studies may be taken up overcoming these drawbacks.

\section{ACKNOWLEDGEMENTS}

Authors thank their colleagues from the Departments of Pharmacology, Ophthalmology, Community Medicine of Vinayaka Mission's Kirupananda Variyar Medical College, Salem, Tamilnadu, India. Authors would be failing in this duty if they do not thank all their patients included in this study.

Funding: No funding sources

Conflict of interest: None declared

Ethical approval: The study was approved by the Institutional Ethics Committee of Vinayaka Mission's Kirupananda Variyar Medical College, Salem, India

\section{REFERENCES}

1. Towards universal eye health: a global action plan for 2014-2019. Geneva: World Health Organization; $2013 . \quad$ Available at: http://apps.who.int/iris/handle/10665/150155. Accessed 15 May 2018.

2. International Agency for the Prevention of Blindness: 2010 report. London: International Agency for the Prevention of Blindness; 2010. Available at: http://www.iapb.org/sites/iapb.org/files/State\%20of\% 20the\%20World\%20Sight_2010.pdf. Accessed 15 May 2018.

3. Behndig A, Montan P, Stenevi U, Kugelberg M, Lundström M. One million cataract surgeries: Swedish National Cataract Register1992-2009. J Cataract Refract Surg. 2011;37:1539-45.

4. Gupta SK, Kumar A, Kumar D, Agarwal S. Manual small incision cataract surgery under topical anesthesia with intracameral lignocaine: Study on pain evaluation and surgical outcome, Indian J Ophthalmol. 2009 Jan-Feb;57(1):3-7.

5. Ruit S, Tabin G, Chang D, Bajracharya L, Kline DC, Richheimer $\mathrm{W}$, et al. A prospective randomized clinical trial of phacoemulsification vs manual sutureless small-incision extracapsular cataract surgery in Nepal. Ame J of Ophthalmolo. 2007 Jan $1 ; 143(1): 32-8$.

6. Fernandez SA, Dios E, Diz JC. Comparative study of topical anesthesia with Lidocaine $2 \%$ vs. levobupivacaine $0.75 \%$ in cataract surgery. Bri $\mathrm{J}$ of Anesthe. 2009;102(2):216-20.

7. Fichman RA. Use of topical anesthesia alone in cataract surgery. J of Cat Refract Surger. 1996;22:6124.

8. Jacobi PC, Dietlein TS, Jacobi FK. A comparative study of topical vs. retro bulbar anesthesia in complicated cataract surgery. Archives of Ophthalmology. 2000;118:1037-43.

9. Rocha G, Turner C. Safety of cataract surgery under topical anesthesia with oral sedation without anesthetic monitoring. Can $\mathrm{J}$ of Ophthalmolo. 2007;42:288-94.

10. Grabow HB. Topical anesthesia for cataract surgery. Eur J of Implant and Refract Surger. 1993;5:20-4.

11. Fichman RA. Topical eye drops replace injection for anesthesia. Ocular Surgery News March. 1992;20-1.

12. Roman S, Sit DAC, Boureau CM. Sub-Tenon anesthesia: an efficient and safe technique. Bri $\mathbf{J}$ of Ophthalmolo. 1997;81:673-6. 
13. Howard A, Koch PS. Tetravisc versus Lidocaine $2 \%$ jelly as a topical anesthetic agent. J Catar Ref Surge. 2007;33:98-100.

14. Bellucci R, Bellucci F. Comparative efficacy of topical tetracaine solution versus Lidocaine gel in cataract surgery. Open Access Surgery. 2012;5:1-8.

15. Bardocci A, Lofoco G, Perdicaro S, Ciucci F, Manna L. Lidocaine $2 \%$ gel versus lidocaine $4 \%$ unpreserved drops for topical anesthesia in cataract surgery: a randomized controlled trial. Ophthalmology. 2003 Jan 1;110(1):144-9.

Cite this article as: Krishnan P, Sam SM, Kuriachan S, Sethuraman N. A study on the effect of topical lidocaine gel versus drops on surgeon's comfort during manual small incision cataract surgery. Int $\mathrm{J}$ Basic Clin Pharmacol 2018;7:1485-9. 